\title{
Resaerch Paper: The Role of Parental Bonding Perception in Predicting Communication Patterns of Couples
}

\author{
Ghazaleh Sadat Hazarati Ehsanifard $^{1}$ (D), Mansoureh Sadat Sadeghi ${ }^{\text {* }}$ (D) Leili Panaghi $^{1}$ (D)
}

1. Department of Psychology, Family Research Institute, Shahid Beheshti University, Tehran, Iran.

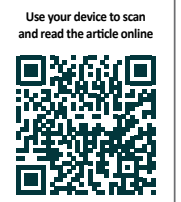

Ctation Hazarati Ehsanifard GS, Sadeghi MS, Panaghi L. The Role of Parental Bonding Perception in Predicting Communication Patterns of Couples. Journal of Health Research. 2021; 11(1):21-28. http://dx.doi.org/10.32598/JRH.11.1.1618.1

http://dx.doi.org/10.32598/JRH.11.1.1618.1

(c) (1) (8)

Article info:

Received: 02 Dec 2018

Accepted: 24 Nov 2019

Publish: 01 Feb 2021

\section{Keywords:}

Communication

pattern, Parental

bonding perception,

Communication pattern of couples

\section{A B STRACT}

Background: Parental bonding perception leads to different domains in future life. The goal of this study was to investigate the role of parental bonding perception in predicting the communication patterns of couples in Tehran.

Methods: This correlational and descriptive study was done on 338 individuals in Tehran, Iran who voluntarily participated in the research in 2016. Communication Pattern Questionnaire (CPQ) and Parental Bonding Instrument (PBI) were used to collect data. Pearson correlation method and multiple regression were used for data analysis using the SPSS V. 22 software.

Results: Data revealed that in the husband group, father care was the only predictor of higher scores of the mutual constructive communication pattern. In the group of wives, father indifference was the predictor of lower scores of constructive communication pattern and mother encouragement of dependency was the predictor of the higher scores of the constructive communication pattern. Mother encouragement of autonomy was the only predictor of lower scores of husband demand/ wife withdraws but no variable predicted wife demand/ husband withdraw pattern. In addition, fathers' encouragement of autonomy in husbands was predictive of spouses' constructive communication patterns. Also, fathers' encouragement of autonomy in husbands was predictive of spouses' constructive communication patterns.

Conclusion: The association between parental bonding perception and couple's communication patterns highlight the importance of early years of childhood and parent-child relationship in future life.

\section{Introduction}

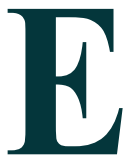

arly experiences of children in their family of origin play a crucial role in their future life. Prior studies have revealed that early parent-child relationship contributes to the children's future adaptation to the environment and to the peer groups during childhood and adolescence $[1$, 2], also to their adaptation to the marital and romantic relationships [3]. Not only parental bonding, but also the perception of parental bonding contributes to the various domains of future life such as marital satisfaction [4],

\section{* Corresponding Author:}

Mansoure Sadat Sadeghi, PhD.

Address: Department of Psychology, Family Research Institute, Shahid Beheshti University, Tehran, Iran.

Phone: +98 (21) 29902387

E-mail:m.sadeghi@sbu.ac.ir 
emotional development [5], and communication patterns [6]. Prior researches show that in many dyadic conflicts, the family of origin and the perception of parental bonding plays a key role $[7,8]$. The hostile relationship of the parent and the child is a base for a future hostile relationship with others and especially with the dyadic relationship. Perception of parental bonding will have an important effect on different dimensions of a couple's relationship.

Communication patterns refer to the conflict-resolution strategies and the ways of interaction and communication in intimate relationships [7]. Christensen and Shenk [8] defined four communication patterns in marital relationships, including: A. Mutual constructive communication refers to the mutual discussion about problems, understanding of the views, expression of the feelings, negotiating a solution, and resolution of problems; B. Mutual avoidance refers to mutual avoidance of discussion, mutual withdrawal after discussion, and mutual withdrawal after discussion; C. Husband demand/ wife withdraw communication refers to the asymmetrical behaviors, in which husband presses wife to discuss a difficulty and then criticizes, nags, and makes demands on her, while the wife withdraws and refuses to further discuss the problem; d. Wife demand/ husband withdraw communication, which is similar to the previous communication pattern but the wife and husband are in opposite roles.

Studies have investigated the role of early parent-child relationships in future marital relationships. It has been reported that adolescent girls' relationship with parents shapes the quality of the romantic relationship that older adolescent girls establish. In addition, girls' better quality of relationship with the mother is associated with delays in girls' entrance into a sexual relationship [9]. Unpleasant experiences in the family is a heritage that people bring into their future dyadic relationship [10].

Another study has investigated whether detrimental childhood relationships with parents in the early years of life are associated with partner relationship quality and emotional adjustment in adulthood and reported that negative parent-child bonds are associated with lowquality partner relationships and dissatisfaction with life in adulthood [10]. Similarly, another study has examined adolescent girls' romantic competence considering the role of divorce, quality of parenting, and maternal romantic history, and approved the prominent role of family relationships in fostering romantic competence among adolescent girls [11].

Another study reported that a distant father-child relationship during adolescence is linked to a child's anxious in love in the future [12]. It has also been found that three developmental trajectories of parent-child relationships in adolescence are linked to the quality of romantic outcomes in emerging adulthood. Similarly, another study found that the mother-child relationship is associated with the social functioning of children [13]. Other studies have found that the perception of the parent-child relationship is contributed to some psychological disorders in the future life of children $[14,15]$.

Because many dyadic conflicts have a root in the family of origin, and the hostile parent-child relationship is a basis for the person's future hostile communication patterns with the friends, coworkers, and husband/wife, we focused on the association between parental bonding perception and communication pattern. Although a few studies have focused on the association between parent-child relationships and romantic relationships in adulthood, we found no prior studies to investigate the association of parental bonding perception with the communication patterns of couples. This study is also the first study in Iran to investigate the association between parental bonding perception and communication patterns. Therefore, in the present study, we investigated the role of parental bonding perception in predicting communication patterns of couples in Tehran, Iran.

\section{Methods}

The current research was a descriptive and correlational study conducted on couples in Tehran $(n=338)$ who participated voluntarily in the research in 2016. Multi-stage sampling was used for sampling. Next, five districts were randomly selected from 22 districts of Tehran and five west, east, north, south, and downtown areas. From each district, four streets were randomly selected and questionnaires were distributed to the houses located in the streets. In the first stage, of 200 selected couples, 150 couples returned the questionnaire, and 87 couples (i.e. 174 questionnaires) remained after excluding the incomplete questionnaire. In the second stage, 150 couples (300 questionnaires) were chosen and 112 couples (224 questionnaires) returned the questionnaires and 82 couples (164 questionnaires) remained after excluding incomplete questionnaires. Therefore, the final sample was 169 couples (338 questionnaires). There is a consensus that in regression analysis, a sample size of more than 200 is acceptable. Participants participated voluntarily and all data were kept confidential. Before the study, participants signed an informed consent form. The inclusion criteria were as follows: A. Having at least a high school diploma; B. First-married participants; C. having parents alive during childhood and adolescence; 
and $d$. passing at least two years of marriage. The exclusion criteria were a. No history of psychiatric disorders; b. Divorce; and c. Marital infidelity. Using the SPSS V. 22 software, the Pearson correlation and multiple regression analysis were used for data analysis.

\section{Measures}

Communication Pattern Questionnaire (CPQ): CPQ is a 35-item questionnaire with published evidence on its reliability [16] and was designed by Christensen and Sullaway [17] to examine spouses' perception of marital interactions. This questionnaire measures marital interaction in three stages, including A. when a problem arises; B. when spouses discuss marital relationship problems; and C. after discussion regarding marital relationship problems. The spouses answer each question on a 9-point Likert ranging from 1 "very unlikely" to 9 "very likely". CPQ is comprised of 3 items, including: A. mutual constructive communication; B. mutual avoidance; and C. demand/ withdraw communication, which contains two forms of husband demand/ wife withdraw and wife demand/ husband withdraw. The Persian version of the CPQ with published evidence of its reliability [18] was used in this study and showed a good concurrent validity with other scales and Cronbach's alpha was 0.76 for the whole scale and 0.76 for both men and women. The Cronbach's alpha was $0.69,0.79$, and 0.77 , respectively for mutual constructive communication, mutual avoidance, and demand/ withdraw communication patterns.

Parental Bonding Instrument (PBI): PBI was designed by Parker [19] and measures fundamental parental dimensions of care and protection. PBI is comprised of 25 items, including 12 items regarding "care" and 13 items regarding "overprotection". Respondents answered each question on a four-point Likert scale ranging from "very unlike" (0) to "very like" (3). Respondents were asked to remember their first 16 years of life and score their parent's behaviors and attitudes. The psychometric properties of the original [20] and the Persian version [21] of the CPQ have been confirmed. Confirmatory factor analysis showed that the Persian version has four subscales, including encouraging dependency, encouraging autonomy, indifference, and care. It showed good concurrent validity and the Cronbach's has been reported 0.84 for the whole scale, and $0.71,0.89,0.81,0.85$, respectively for subscales of encouraging dependency, encouraging autonomy, indifference, and care [21]. Regression analysis was used to predict the subscales of communication patterns of the person or his/her spouse from subscales of PBI in both men and women.

\section{Results}

The demographics of the participants are shown in Table 1 . First, we checked the data for the regression analysis hypotheses. The correlation matrices for the groups of husbands and wives are shown separately in Tables 2 and 3. The data also were screened for the outliers using Mahalanobis distance and no outliers were detected. Another assumption was the normality of the data. The Kolmogorov-Smirnov test was used to test the normality of the data, which was not meaningful $(\mathrm{P}=0.23)$ and the normality of the data was proved. Our first hypothesis was that how the perception of parental bonding predicts the communication patterns of the person. The results of the regression analysis for predicting mutual constructive communication pattern are shown in Table 4.

As shown in Table 4, our results indicated that in the group of husbands, father care was the only predictive

Table 1. Demographics of the participants, Tehran, Iran (N=338)

\begin{tabular}{|c|c|c|c|}
\hline & \multirow{2}{*}{ Variables } & \multicolumn{2}{|c|}{ No. (\%) } \\
\hline & & Men & Women \\
\hline & Age (y/Std) & 39.04 (9.93) & $34.96(9.20)$ \\
\hline \multirow{5}{*}{ Education (Freq/percent) } & High school diploma or associate degree & $102(60.3)$ & $98(58)$ \\
\hline & Bachelor's degree & $43(25.4)$ & $58(34.3)$ \\
\hline & MSc. or PhD. & $24(14.3)$ & $13(7.7)$ \\
\hline & Average duration of marriage (years/Std) & $13(10.14)$ & $13(10.14)$ \\
\hline & Average number of children & 1 & 1 \\
\hline
\end{tabular}


Table 2. The correlation between parental bonding perception and communication patterns in the group of husbands

\begin{tabular}{|c|c|c|c|c|c|c|c|c|c|c|c|}
\hline Variables & 1 & 2 & 3 & 4 & 5 & 6 & 7 & 8 & 9 & 10 & 11 \\
\hline Care (father) & 1 & & & & & & & & & & \\
\hline $\begin{array}{l}\text { Encouraging depen- } \\
\text { dency (father) }\end{array}$ & 0.04 & 1 & & & & & & & & & \\
\hline $\begin{array}{l}\text { Encouraging au- } \\
\text { tonomy (father) }\end{array}$ & $0.40^{* *}$ & $-0.29^{* *}$ & 1 & & & & & & & & \\
\hline Indifference (father) & $-0.62^{* *}$ & $-0.20^{* *}$ & $-0.22^{* *}$ & 1 & & & & & & & \\
\hline Care (mother) & 0.10 & $-0.41^{* *}$ & $0.17^{*}$ & $-0.32^{* *}$ & 1 & & & & & & \\
\hline $\begin{array}{l}\text { Encouraging depen- } \\
\text { dency (mother) }\end{array}$ & -0.13 & $0.46^{* *}$ & $-0.21^{* *}$ & $0.17^{*}$ & -0.10 & 1 & & & & & \\
\hline $\begin{array}{l}\text { Encouraging au- } \\
\text { tonomy (mother) }\end{array}$ & 0.14 & -0.08 & $0.46^{* *}$ & -0.07 & 0.39 & 0.06 & 1 & & & & \\
\hline $\begin{array}{l}\text { Indifference } \\
\text { (mother) }\end{array}$ & -0.03 & $0.51^{* *}$ & -0.13 & $0.32^{* *}$ & $-0.56^{* *}$ & $0.56^{* *}$ & 0.10 & 1 & & & \\
\hline $\begin{array}{l}\text { Mutual constructive } \\
\text { communication }\end{array}$ & 0.11 & -0.02 & -0.04 & -0.01 & 0.06 & -0.05 & 0.09 & -0.07 & 1 & & \\
\hline $\begin{array}{l}\text { Wife demand. hus- } \\
\text { band withdraw }\end{array}$ & -0.01 & 0.11 & -0.06 & -0.01 & 0.02 & 0.10 & 0.06 & 0.10 & 0.07 & 1 & \\
\hline $\begin{array}{l}\text { Husband demand. } \\
\text { wife withdraw }\end{array}$ & -0.13 & 0.06 & -0.11 & 0.13 & -0.15 & 0.04 & -0.06 & 0.05 & 0.07 & $0.37^{* *}$ & 1 \\
\hline
\end{tabular}

${ }^{*} \mathrm{P}<0.05 ;{ }^{* *} \mathrm{P}<0.01$.

MPH

variable of mutual constructive communication. Our findings also demonstrated that none of the variables were predictive of wife demand/ husband withdraw and husband demand/ wife withdraw. In the group of wives, father indifference and mother encouragement of dependency were predictors of constructive communication pattern. Mother encouragement of autonomy was the only predictor of husband demand/ wife withdraw but no variable predicted wife demand/ husband withdraw pattern.

Our second hypothesis was how the perception of parental bonding predicts the communication patterns of the spouse. The results of the regression analysis for constructive communication pattern are shown in Table 5.

Table 3. The correlation between parental bonding perception and communication patterns in the group of wives

\begin{tabular}{|c|c|c|c|c|c|c|c|c|c|c|c|}
\hline Variables & 1 & 2 & 3 & 4 & 5 & 6 & 7 & 8 & 9 & 10 & 11 \\
\hline Care (father) & 1 & & & & & & & & & & \\
\hline $\begin{array}{l}\text { Encouraging depen- } \\
\text { dency (father) }\end{array}$ & 0.09 & 1 & & & & & & & & & \\
\hline $\begin{array}{l}\text { Encouraging au- } \\
\text { tonomy (father) }\end{array}$ & $0.50 * *$ & $-0.20 * *$ & 1 & & & & & & & & \\
\hline Indifference (father) & $-0.53^{* *}$ & $0.18^{*}$ & $-0.30 * *$ & 1 & & & & & & & \\
\hline Care (mother) & 0.15 & $-0.42^{* *}$ & $0.22 * *$ & $-0.33^{* *}$ & 1 & & & & & & \\
\hline $\begin{array}{l}\text { Encouraging depen- } \\
\text { dency (mother) }\end{array}$ & 0.03 & $0.45^{* *}$ & $-0.18^{*}$ & 0.11 & $-0.18^{*}$ & 1 & & & & & \\
\hline $\begin{array}{l}\text { Encouraging au- } \\
\text { tonomy (mother) }\end{array}$ & 0.12 & -0.08 & $0.36 * *$ & -0.10 & $0.43 * *$ & -0.12 & 1 & & & & \\
\hline $\begin{array}{l}\text { Indifference } \\
\text { (mother) }\end{array}$ & -0.06 & $0.42 * *$ & $-0.17^{*}$ & $0.24 * *$ & $-0.64 * *$ & $0.56 * *$ & -0.06 & 1 & & & \\
\hline $\begin{array}{l}\text { Mutual constructive } \\
\text { communication }\end{array}$ & 0.11 & -0.01 & 0.10 & $-0.20 * *$ & 0.10 & $-0.21 * *$ & $0.16^{*}$ & -0.11 & 1 & & \\
\hline $\begin{array}{l}\text { Wife demand. hus- } \\
\text { band withdraw }\end{array}$ & 0.01 & 0.04 & -0.08 & 0.04 & -0.01 & 0.06 & $-0.17^{*}$ & -0.03 & -0.01 & 1 & \\
\hline $\begin{array}{l}\text { Husband demand. } \\
\text { wife withdraw }\end{array}$ & -0.03 & 0.01 & -0.03 & 0.07 & -0.07 & 0.05 & $-0.25 * *$ & -0.06 & -0.12 & $0.31 * *$ & 1 \\
\hline
\end{tabular}

${ }^{*} \mathrm{P}<0.05 ; * * \mathrm{P}<0.01$ 
Table 4. The results of regression analysis for predicting mutual constructive communication pattern

\begin{tabular}{ccccc}
\hline Variables & Unstandardized Beta & Estimated Standard Error & Standard Beta & Semi-partial Coefficient \\
\hline Constant & 11.036 & 3.549 & - & - \\
\hline Care (father) & 0.122 & 0.135 & 0.101 & 0.070 \\
\hline $\begin{array}{c}\text { Encouragement of dependency } \\
\text { (father) }\end{array}$ & -0.089 & 0.132 & -0.146 & -0.111 \\
\hline $\begin{array}{c}\text { Encouragement of autonomy } \\
\text { (father) }\end{array}$ & 0.018 & 0.008 & $0.229 * *$ & 0.177 \\
\hline $\begin{array}{c}\text { Indifference (father) } \\
\text { Care (mother) }\end{array}$ & -0.279 & 0.240 & -0.127 & -0.090 \\
\hline $\begin{array}{c}\text { Encouragement of Dependency } \\
\text { (mother) }\end{array}$ & 0.047 & 0.182 & 0.035 & 0.029 \\
\hline $\begin{array}{c}\text { Encouragement of autonomy } \\
\text { (mother) }\end{array}$ & 0.191 & 0.152 & 0.015 & 0.011 \\
\hline Indifference (mother) & -0.213 & 0.197 & 0.109 & 0.075 \\
\hline
\end{tabular}

${ }^{*} \mathrm{P}<0.05 ;{ }^{* *} \mathrm{P}<0.01$

unA

Table 5. The results of the regression analysis for predicting mutual constructive communication of spouses

\begin{tabular}{|c|c|c|c|c|}
\hline Variables & Unstandardized Beta & Estimated Standard Error & Standard Beta & Semi-partial Coefficient \\
\hline Constant & 19.178 & 3.441 & - & - \\
\hline Care (father) & -0.276 & 0.127 & $-0.245^{*}$ & -0.169 \\
\hline $\begin{array}{l}\text { Encouragement of Depen- } \\
\text { dency (father) }\end{array}$ & 0.163 & 0.124 & 0.135 & 0.102 \\
\hline $\begin{array}{l}\text { Encouragement of autonomy } \\
\text { (father) }\end{array}$ & 0.001 & 0.007 & 0.019 & 0.015 \\
\hline Indifference (father) & -0.468 & 0.226 & $-0.228^{*}$ & -0.161 \\
\hline Care (mother) & 0.272 & 0.171 & 0.216 & 0.124 \\
\hline $\begin{array}{l}\text { Encouragement of Depen- } \\
\text { dency (mother) }\end{array}$ & 0.297 & 0.143 & $0.221^{*}$ & 0.161 \\
\hline $\begin{array}{l}\text { Encouragement of autonomy } \\
\text { (mother) }\end{array}$ & -0.336 & 0.186 & -0.206 & -0.141 \\
\hline Indifference (mother) & 0.368 & 0.181 & $0.296 *$ & 0.158 \\
\hline
\end{tabular}

$* \mathrm{P}<0.05 ;{ }^{* *} \mathrm{P}<0.01$.

ung

According to Table 5, fathers' encouragement of autonomy in husbands was predictive of spouses' constructive communication patterns. Our data analysis also revealed that no variable was the predictor of the wife demand/ husband withdraw and husband demand/ wife withdraw pattern.

\section{Discussion}

Our results revealed that in the husbands group, father care was the only predictor of higher scores of the mutual constructive communication pattern. In the group of wives, father indifference was the predictor of lower scores of constructive communication pattern and moth- er encouragement of dependency was the predictor of the higher scores constructive communication pattern. Mother encouragement of autonomy was the only predictor of lower scores of husband demand/ wife withdraw but no variable predicted wife demand/ husband withdraw pattern. To our knowledge, our finding was first in investigating the association of perception of parental bonding and spouse's communication patterns. We found that the father's encouragement of autonomy in husbands was predictive of the spouse's constructive communication patterns, but no variable was the predictor of other subscales of communication pattern in spouses. 
Our results are in line with previous studies, which highlighted the importance of the father-girl relationship in the girl s' successful relationships with their partners. One study found that girls' success in establishing a safe relationship with men contribute to the acceptance of the girl from his father. Another study reported that a distant fatherchild relationship during adolescence is associated with a child's anxious in love in future [12]. Regarding the association of the mother-girl relationship to communication patterns, our data was in line with the prior literature [13].

We also found that mother encouragement of autonomy was the only predictor of lower scores of husband demand/ wife withdraw. Our results are in line with the explanation by Martin and Bird [22] regarding husband demand/ wife withdraw pattern. They stated that in this pattern, the wife has lower self-esteem and complains that she does not receive love from her husband. Our data converge with these findings, indicating mother encouragement of autonomy results in increased self-esteem and a decrease in the pattern of husband demand/ wife withdraw.

Our results are consistent with previous studies showing that the parent-child relationship is associated with communication patterns in the future periods of children's lives. Shulman et al. [11] examined adolescent girls' romantic competence considering the role of divorce, quality of parenting, and maternal romantic history and highlighted the crucial role of family relationships in fostering romantic competence among adolescent girls.

A prior study also highlighted the importance of perception of parental bonding rather than the real parent-child relationship in the future life of children and reported that perception of the parent-child relationship is associated with some psychological disorders in the future life of children $[13,14]$. The lack of a strong association between parental bonding and future communication patterns in the marital relationship is consistent with the study by Hare et al. [23], which found an intergenerational transmission of aggression in romantic relationships. Similarly, our study is consistent with the attachment theory of Bowlby [24], in which it was hypothesized that the intergenerational transmission of psychological problems is due to parenting and attachment styles. Our findings showed that parental bonding perception plays a prominent role in predicting the communication patterns of individuals. As previous research showed [9], children's good communication patterns with their parents, are linked to the future higher performance in their close relationships. Parental bonding perception is highly important in determining emotional and communication patterns [14].
The perception of parental bonding is more important than parental boding itself [14]. In some cases, parents report that they have a close relationship with their parents while the children do not accept it [22]. The perception of parental bonding deals with the perception of the children of their relationship with their parents, which can have a significant impact on the development of the children and their future life. When the children get older and become parents, they tend to use the same strategies as their parents used and this communication pattern will continue in the next generations [23].

We can further explain these results regarding Bowlby's theory of attachment. Bowlby's theory of attachment declares that children build a functional model of their first experiences with their caregivers [24]. Although the literature pays little attention to the father's role in children's upbringing, the father has a significant impact on the psychological development of children as an authoritative caregiver [23]. As a result, boys' relationship with their fathers is considerably significant and needs more attention.

One of the limitations of this study was that some of the occupied men and women were not at home when data collectors referred, which may threaten the generalizability of the findings to the whole population. Another limitation was the cross-sectional nature of the study. Despite these limitations, our findings added to the understandings of the relationship between perception of parental bonding and the couple's communication patterns.

\section{Conclusion}

We found that in the husbands group, father care was the only predictive variable of mutual constructive communication. In the group of wives, father indifference and mother encouragement of dependency were predictors of the constructive communication pattern. Mother encouragement of autonomy was the only predictor of husband demand/ wife withdraw but no variable predicted wife demand/ husband withdraw pattern. Our findings regarding the prediction of spouse's communication pattern with parental bonding showed that fathers' encouragement of autonomy in husbands was predictive of spouses' constructive communication patterns. The association between parental bonding perception and couple's communication patterns highlight the importance of the early years of childhood and the parent-child relationship in future life. 


\section{Ethical Considerations}

\section{Compliance with ethical guidelines}

The study was approved with the ethics code of 94-0355-29577.

Funding

This research did not receive any grant from funding agencies in the public, commercial, or non-profit sectors.

\section{Authors' contributions}

Study design: Ghazaleh Sadat Hazarati Ehsani Fard and Mansoure Sadat Sadeghi; Data collection and data analysis: Ghazaleh Sadat Hazarati Ehsanifard, Leili Panaghi; Writing - original draft: Ghazaleh Sadat Hazarati Ehsanifard, Mansoure Sadat Sadeghi.

\section{Conflict of interest}

The authors declared no conflict of interest.

\section{Acknowledgments}

The authors are grateful to all participants for taking part in this research. The authors do not mention any real or perceived vested interests that may be viewed as a conflict of interest in this article.

\section{References}

[1] McAdams TA, Rijsdijk FV, Narusyte J, Ganiban JM, Reiss D, Spotts E, et al. Associations between the parent-child relationship and adolescent self-worth: A genetically informed study of twin parents and their adolescent children. J Child Psychol Psychiatry. 2017; 58(1):46-54. [DOI:10.1111/jcpp.12600] [PMID] [PMCID]

[2] Pourhossein R, Habibi M, Ashoori A, Ghanbari N, Riahi Y, Ghodrati S. Prevalence of behavioral disorders among preschool children. J Fundam Mental Health. 2015; 17(5):234-9. [DOI: 10.22038/JFMH.2015.4794]

[3] Whitton SW, Waldinger RJ, Schulz MS, Allen JP, Crowell JA, Hauser ST. Prospective associations from family-of-origin interactions to adult marital interactions and relationship adjustment. J Fam Psychol. 2008; 22(2):274-86. [DOI:10.1037/08933200.22.2.274] [PMID] [PMCID]

[4] Feldman R. Parents' convergence on sharing and marital satisfaction, father involvement, and parent-child relationship at the transition to parenthood. Infant Ment Health J. 2000; 21(3):176-91. [DOI:10.1002/1097-0355(200007)21:33.0.CO;2-4]
[5] Catalano RF, Oesterle S, Fleming CB, Hawkins JD. The importance of bonding to school for healthy development: Findings from the Social Development Research Group. J Sch Health. 2004 74(7):252-61. [DOI:10.1111/j.1746-1561.2004.tb08281.x] [PMID]

[6] Skowron EA, Stanley KL, Shapiro MD. A longitudinal perspective on differentiation of self, interpersonal and psychological well-being in young adulthood. Contemp Fam Ther. 2009; 31(1):3-18. [DOI:10.1007/s10591-008-9075-1]

[7] Koerner AF, Schrodt P, Fitzpatrick MA. Family communication patterns theory: A grand theory of family communication. In: Braithwaite DO, Suter EA, Floyd K, editors. Engaging theories in family communication. $2^{\text {th }}$ ed. England: Routledge; 2017. [DOI:10.4324/9781315204321]

[8] Durtschi JA, Soloski KL, Kimmes J. The dyadic effects of supportive coparenting and parental stress on relationship quality across the transition to parenthood. J Marital Fam Ther. 2017; 43(2):308-21. [DOI:10.1111/jmft.12194] [PMID]

[9] Scharf M, Mayseless O. Late adolescent girls' relationships with parents and romantic partner: The distinct role of mothers and fathers. J Adolesc. 2008; 31(6):837-55. [DOI:10.1016/j.adolescence.2008.06.012] [PMID]

[10] Overbeek G, Stattin H, Vermulst A, Ha T, Engels RCME. Parent-child relationships, partner relationships, and emotional adjustment: A birth-to-maturity prospective study. Dev Psychol. 2007; 43(2):429-37. [DOI:10.1037/0012-1649.43.2.429] [PMID]

[11] Shulman S, Zlotnik A, Shachar-Shapira L, Connolly J, Bohr Y Adolescent daughters' romantic competence: The role of divorce, quality of parenting, and maternal romantic history. J Youth Adolesc. 2012; 41(5):593-606. [DOI:10.1007/s10964-012-9748-9] [PMID]

[12] Seiffge-Krenke I, Overbeek G, Vermulst A. Parent-child relationship trajectories during adolescence: Longitudinal associations with romantic outcomes in emerging adulthood. J Adolesc 2010; 33(1):159-71. [DOI:10.1016/j.adolescence.2009.04.001] [PMID]

[13] Smith LE, Greenberg JS, Seltzer MM, Hong J. Symptoms and behavior problems of adolescents and adults with autism: Effects of mother-child relationship quality, warmth, and praise. Am J Ment Retard. 2008; 113(5):387-402. [DOI:10.1352/2008.113:387402] [PMID] [PMCID]

[14] Arrindell WA, Emmelkamp PM, Monsma A, Brilman E. The role of perceived parental rearing practices in the aetiology of phobic disorders: A controlled study. Br J Psychiatry. 1983; 143(2):183-7. [DOI:10.1192/bjp.143.2.183] [PMID]

[15] Harris AE, Curtin L. Parental perceptions, early maladaptive schemas, and depressive symptoms in young adults. Cognit Ther Res. 2002; 26(3):405-16. [DOI:10.1023/A:1016085112981]

[16] Noller P, White A. The validity of the communication patterns questionnaire. Psychol Assess. 1990; 2(4):478-82 [DOI:10.1037/1040-3590.2.4.478]

[17] Heavey CL, Larson BM, Zumtobel DC, Christensen A. The Communication Patterns Questionnaire: The reliability and validity of a constructive communication subscale. J Marriage Fam. 58(3):796-800. [DOI:10.2307/353737]

[18] Samadzadeh M, Shaieri MR, Javidi N. [Communication patterns questionnair: The reliability and validity (Persian)]. Fam Couns Psychother. 2013; 3(1):124-50. http://fcp.uok.ac.ir/article $9782 . \mathrm{htm}$ 
[19] Parker G. The parental bonding instrument: Psychometric properties reviewed. Psychiatr Dev. 1989; 7(4):317-35. [PMID]

[20] Parker G. The parental bonding instrument. A decade of research. Soc Psychiatry Psychiatr Epidemiol. 1990; 25(6):281-2. [DOI:10.1007/BF00782881] [PMID]

[21] Behzadi B, Parker G. A Persian version of the parental bonding instrument: Factor structure and psychometric properties. Psychiatry Res. 2015; 225(3):580-7. [DOI:10.1016/j.psychres.2014.11.042] [PMID]

[22] Young ME, Long LL. Counseling and therapy for couples. Belmont, CA: Thomson Brooks/Cole Publishing Co; 1998. https://www.worldcat.org/title/counseling-and-therapyfor-couples/oclc/70847905

[23] Martin PA, Bird HW. A marriage pattern: The "lovesick" wife and the "cold, sick" husband. Psychiatry. 1959; 22(3):2459. [DOI:10.1080/00332747.1959.11023177] [PMID]

[24] Clifford MD. Four events in the life of John Bowlby: Their contribution to the development of attachment theory. Att: New Dir in Psychother Relat Psychoanal. 2017; 11(1):51-72. [DOI:10.33212/att.v11n1.2017.51] 